\title{
Saccharomyces cerevisiae in the Production of Whisk(e)y
}

\author{
Graeme M. Walker ${ }^{1, *}$ and Annie E. Hill ${ }^{2}$ \\ 1 Division of Food \& Drink, School of Science, Engineering \& Technology, Abertay University, \\ Dundee DD1 1HG, UK \\ 2 International Centre for Brewing \& Distilling, Heriot-Watt University, Riccarton, Edinburgh EH14 4AS, UK; \\ a.hill@hw.ac.uk \\ * Correspondence: g.walker@abertay.ac.uk; Tel.: +44-138-230-8658
}

Academic Editor: Edgar Chambers IV

Received: 14 November 2016; Accepted: 7 December 2016; Published: 20 December 2016

\begin{abstract}
Whisk(e)y is a major global distilled spirit beverage. Whiskies are produced from cereal starches that are saccharified, fermented and distilled prior to spirit maturation. The strain of Saccharomyces cerevisiae employed in whisky fermentations is crucially important not only in terms of ethanol yields, but also for production of minor yeast metabolites which collectively contribute to development of spirit flavour and aroma characteristics. Distillers must therefore pay very careful attention to the strain of yeast exploited to ensure consistency of fermentation performance and spirit congener profiles. In the Scotch whisky industry, initiatives to address sustainability issues facing the industry (for example, reduced energy and water usage) have resulted in a growing awareness regarding criteria for selecting new distilling yeasts with improved efficiency. For example, there is now a desire for Scotch whisky distilling yeasts to perform under more challenging conditions such as high gravity wort fermentations. This article highlights the important roles of S. cerevisiae strains in whisky production (with particular emphasis on Scotch) and describes key fermentation performance attributes sought in distiller's yeast, such as high alcohol yields, stress tolerance and desirable congener profiles. We hope that the information herein will be useful for whisky producers and yeast suppliers in selecting new distilling strains of S. cerevisiae, and for the scientific community to stimulate further research in this area.
\end{abstract}

Keywords: Saccharomyces cerevisiae; whisky production; yeast; Scotch whisky

\section{Introduction}

\subsection{Types of Whisk(e)y}

Whisky is a widely consumed global distilled spirit and is one of the highest revenue alcoholic beverages. Whisky (or whiskey, when referring to Irish or American whiskies) derives from the Gaelic uisge beatha, meaning "water of life" and is distilled spirit made from cereals. Scotland produces the most widely exported and most recognised whisky brands and Scotch whiskies represent large sources of revenue and employment in Scotland (see Section 1.2). The Scotch Whisky Regulations 2009 define five categories of Scotch Whisky: Single Malt, Single Grain, Blended, Blended Malt and Blended Grain. For both malt and grain whiskies, production must adhere to the following 2009 regulations which state that "Scotch Whisky":

a. Has been distilled at a distillery in Scotland from water and malted barley (to which only whole grains of other cereals have been added) all of which have been-

$$
\text { processed at that distillery into a mash; }
$$


(ii) converted at that distillery into a fermentable substrate only by endogenous enzyme systems; and

(iii) fermented at that distillery only by the addition of yeast;

b. Has been distilled at an alcoholic strength by volume of less than $94.8 \%$.

Maturation must also take place in Scotland in oak casks of a capacity not exceeding $700 \mathrm{~L}$ and for a period of not less than three years. Such methods of production and maturation should result in a product that retains the colour, aroma and taste derived from the raw materials used.

Ireland, USA and Canada are the other main whisk(e)y producing countries alongside Japan, India and several other countries (Figure 1) and each have their own rules regarding production, labeling and marketing that largely match the Scotch Whisky Regulations. "Irish Whiskey" applies to spirits distilled and matured in Ireland, including Northern Ireland, and which complies with Regulation (EC) No 110/2008 of the European Parliament and of the Council and of the Irish Whiskey Act 1980. There are three varieties of Irish Whiskey: Pot Still, Malt and Grain, each with its own specific technical specifications. Traditionally Irish whiskies are triple distilled, which results in a higher strength final spirit that is light in aroma but sweet in taste due to the ratio of total higher alcohols to esters. In Ireland, however, law does not prescribe triple distillation and double distillation may be employed.

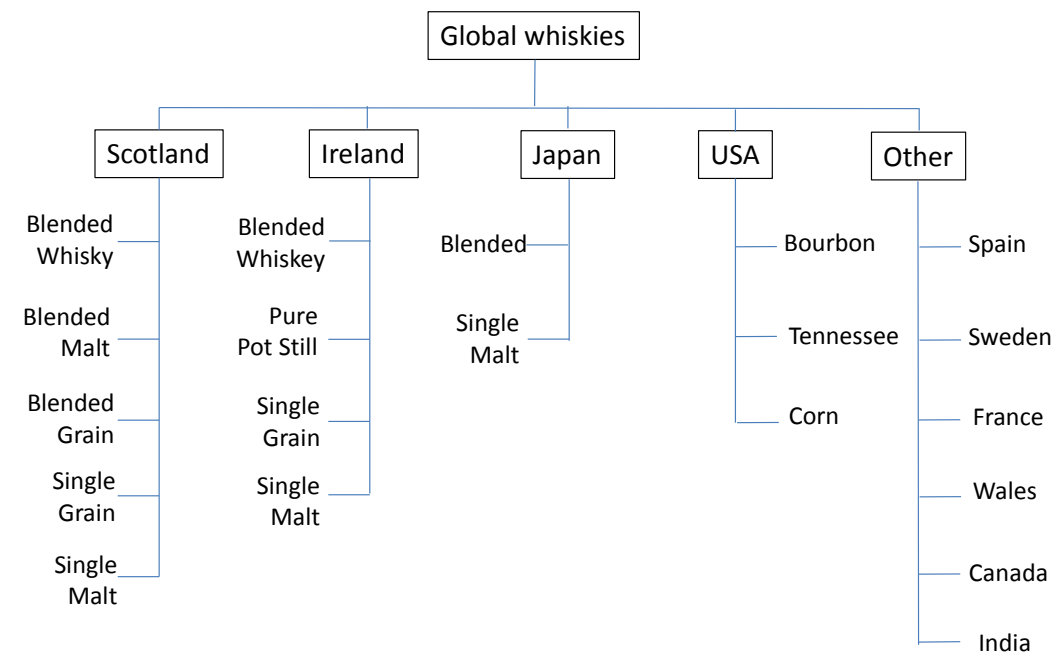

Figure 1. Main whisk(e)y-producing countries.

In the USA, whiskey production and labelling is governed by Title 27 of the US Code of Federal Regulations and is defined as "an alcoholic distillate from a fermented mash of grain produced at less than $190^{\circ}$ proof in such manner that the distillate possesses the taste, aroma, and characteristics generally attributed to whiskey, stored in oak containers and bottled at not less than $80^{\circ}$ proof, and also includes mixtures of such distillates for which no specific standards of identity are prescribed". More specifically, various types of American whiskey are further defined with bourbon, rye, wheat and malt whiskies produced at alcohol strengths not exceeding $160^{\circ}$ proof from a fermented mash of not less than $51 \%$ corn, rye, wheat, malted barley, or malted rye grain, respectively, and stored at not more than $125^{\circ}$ proof in charred new oak containers; and also includes mixtures of such whiskies of the same type. "Corn whisky" is whiskey produced at alcohol strengths not exceeding $160^{\circ}$ proof from a fermented mash of not less than $80 \%$ corn grain, and if stored in oak containers stored at not more than $125^{\circ}$ proof in used or uncharred new oak containers and not subjected in any manner to treatment with charred wood. Distillates that have been produced as defined above and matured for a period of 2 years or more are designated as "straight". Non-matured spirit may be used in "Spirit whisky" which is a mixture of neutral spirits and not less than $5 \%$ on a proof gallon basis of whisky. 
Canadian regulations cover the same requirements as those for other countries in terms of distillation and ageing (e.g., in small wood casks for not less than 3 years). However, the mash may be from "cereal grain or cereal grain products saccharified by the diastase of malt or by other enzymes and fermented by the action of yeast or a mixture of yeast and other micro-organisms". This contrasts with Scotch whisky production where only enzymes derived from endogenous enzyme systems (e.g., malted barley) may be used.

\subsection{Global Production Statistics and Economic Impact}

Scotch whisky currently accounts for nearly one-quarter of all British food and drink exports on an annual basis, and about one-third of exports are destined for the European Union. More than 10,000 people are directly employed in the Scotch whisky industry, many in economically deprived areas, with over 40,000 jobs across the UK supported by the industry (Scotch Whisky Association [1]). France is the biggest export market for Scotch with sales of over 91 million bottles in the first half of 2016. In the same period, the equivalent of 533 million bottles or 149 million litres were shipped from Scotland worldwide, representing sales to a value of $£ 1.7$ billion.

The USA produces approximately 333 million litres of whiskey each year with just two brands, Jack Daniels and Jim Beam, accounting for over 50\% of sales. In Canada, over 189 million litres of rye whisky are produced each year and in Ireland 63 million litres. India is another major producer, but not exporter, of whisky. In addition, many Indian "whiskies" are made from non-cereal raw materials, such as molasses.

\section{Whisky Production Processes}

\subsection{Summary of Whisky Production Processes}

Figure 2 shows the general scheme for the production of various distilled spirits, highlighting the important role of yeast at the fermentations stage.

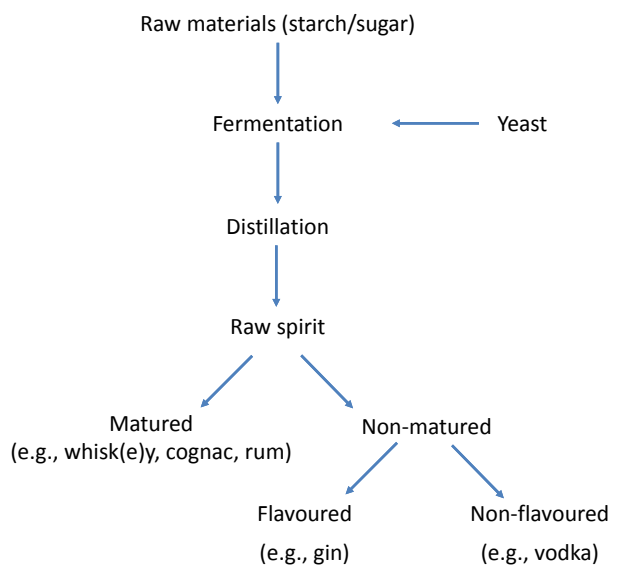

Figure 2. General scheme for the production of distilled spirit beverages.

For Scotch malt whisky, a typical 2-pot distillation process is employed, as shown in Figure 3. The wash (or fermented "beer" produced in a vessel called a washback) is usually at $8 \%-10 \%$ alcohol by volume (abv) prior to distillation. The first distillation is used to produce low wines with an abv of $25 \%-30 \%$. The spirit still is then charged with a blend of low wines from the wash still and foreshots and feints from the previous running of the spirit still. The proportions of each will vary from distillery to distillery. The strength of spirit going into the still will be principally determined by the "cut" points. Each distillery rigidly maintains its own cut points as these determine the character of the spirit. In the spirit still the first cut is typically taken at $70 \%-75 \%$ abv, the middle cut is collected as new-make spirit and the second cut is typically at $62 \%-64 \%$ abv, but can be as low as $57 \%$ abv. 
The process is not linear in that many of the products from one stage are fed back to previous stage(s) in order to maximise yield. For example, foreshots and feints from the spirit still are combined with low wines for redistillation (Figure 3).

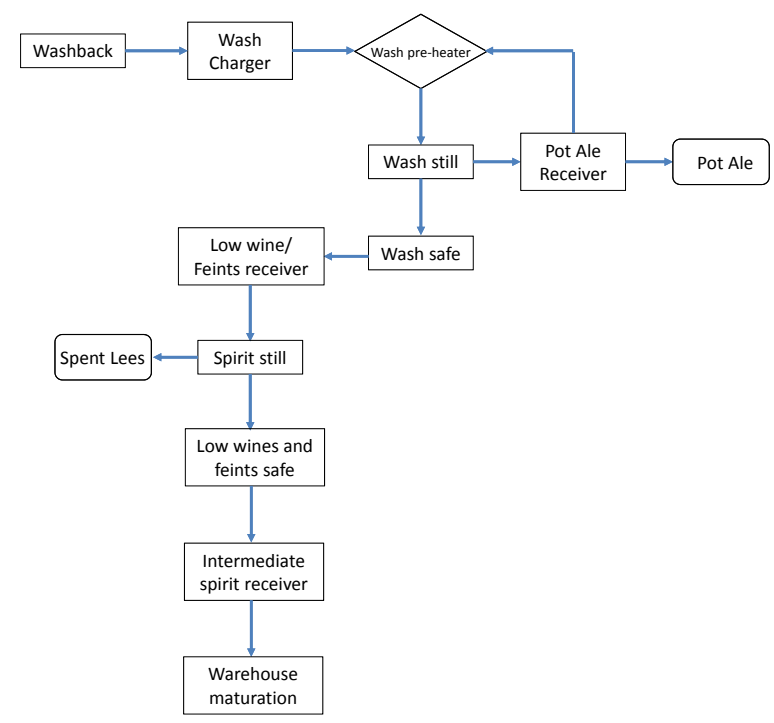

Figure 3. Flow diagram of Scotch malt whisky production (distillation and maturation).

Unlike malt whisky, Scotch grain whisky is produced in a Patent or Coffey Still in a continuous process. A Coffey still consists of two parts-an analyser and a rectifier (see Figure 4). The wash is pumped in at the top of the rectifier where it is warmed as it flows down a coil in the column. The warm wash then enters the top of the analyser and descends through a series of perforated plates. Low pressure steam is pumped in at the bottom of the analyser which rises up through the plates extracting alcohol vapours taking them to the bottom of the rectifier column. As the alcohol vapours rise up through the rectifier they are condensed on trays by the cool wash coils and the grain spirit is removed from the column towards the upper end, typically around 6 trays from the top.

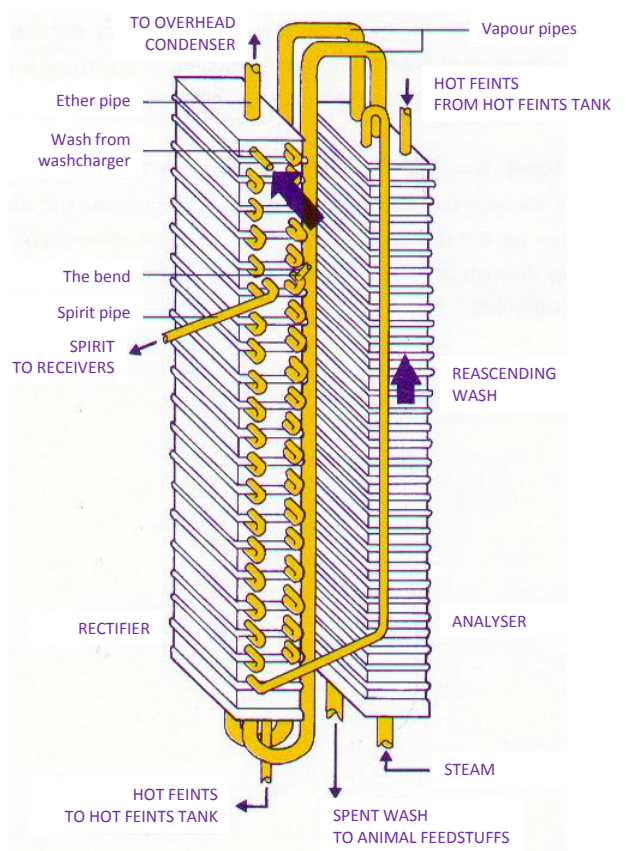

Figure 4. Coffey Still Design (reproduced courtesy of The International Centre for Brewing and Distilling). 


\subsection{Preparation of Fermentable Substrate}

For malt-based spirits, including single malt Scotch whisky, the predominant fermentable sugar is maltose, as shown in Table 1.

Table 1. Approximate sugar composition of an all-malt wort (similar figures apply to grain distillery wort; from Palmer [2]).

\begin{tabular}{cc}
\hline Sugar & Composition \\
\hline Fructose & $1 \%$ \\
Glucose & $10 \%$ \\
Maltose & $46 \%$ \\
Sucrose & $5 \%$ \\
Maltotriose & $15 \%$ \\
Maltotetraose & $10 \%$ \\
Maltopentaose \& higher dextrins & $13 \%$ \\
\hline
\end{tabular}

The wort (or fermentable extract obtained following mashing of the milled grains) is obtained following the saccharification of cereal starch using either endogenous i.e., malt-derived, or exogenous (commercially available) amylolytic enzymes (for most non-Scotch whiskies). For Scotch grain whisky production un-malted cereals (such as wheat and maize), together with sufficient malted barley (normally around $10 \%$ ) can be used to convert the starch into fermentable sugars. While grain distillers in Scotland are not allowed to use process aids such as external enzymes, nutrients or other additives during processing, they can use a wide range of processing options to efficiently extract the starch and convert it to fermentable sugars. However, the enzymes necessary for this are all present in the malted barley that is used in the conversion (mashing) stage of the process, which is also an important source of nutrients (sugars, amino acids, vitamins and minerals) to support yeast fermentation.

Unlike brewing, in malt and grain whisky wort preparation the mashing process does not stop when the wort leaves the mash tun (mashing vessel) because the wort is not boiled. As a result, residual malt enzymes are able to continue their activity in fermentation. During this period a significant amount of the soluble dextrins is broken down contributing additional fermentable material that can increase spirit production by as much as 30\% [3]. In some respects, this resembles Simultaneous Saccharification and Fermentation (SSF) processes typically found in bioethanol (fuel alcohol) plants that process corn, notably in USA.

\section{Whisky Fermentations}

\subsection{Microbiological Aspects}

In Scotch whisky fermentations, there is normally no temperature control, and control of fermentation is achieved by adjusting the wort to a suitable pitching temperature (typically $16-19{ }^{\circ} \mathrm{C}$ ). This is sufficient to achieve a maximum temperature $\left(32-33^{\circ} \mathrm{C}\right)$ that is necessary to conduct efficient fermentation, which normally takes place over 2-3 days, depending on distillery capacity.

In large-scale whisky distilleries, spontaneous fermentations are not conducted and freshly propagated or commercially supplied pure-cultured yeasts are inoculated (pitched) into distillery fermenters as cultures of Saccharomyces cerevisiae. Nevertheless, other microorganisms are present during whisky fermentations due to the lack of a wort boiling stage and it is recognised that limited bacterial activity is an essential part of the craft of malt distilling [4,5]. For example, lactic acid bacteria (LAB) and Leuconostoc spp., if present, can produce lactic and acetic acids, which may be esterified to produce ethyl lactate/acetate, respectively, which impart sweet, fruity, creamy, and pineapple-like flavours [6]. Lactic acid bacteria are also responsible for the formation of $\gamma$-dodecalactone which imparts a "sweet and fatty" characteristic to the spirit [7]. The evolution of LAB during whisky fermentation is depicted in Figure 5, where it can be seen that initially diverse bacterial populations 
gradually decline to give way to selected homofermentative LAB strains capable of surviving on nutrients liberated by dying yeast cells.

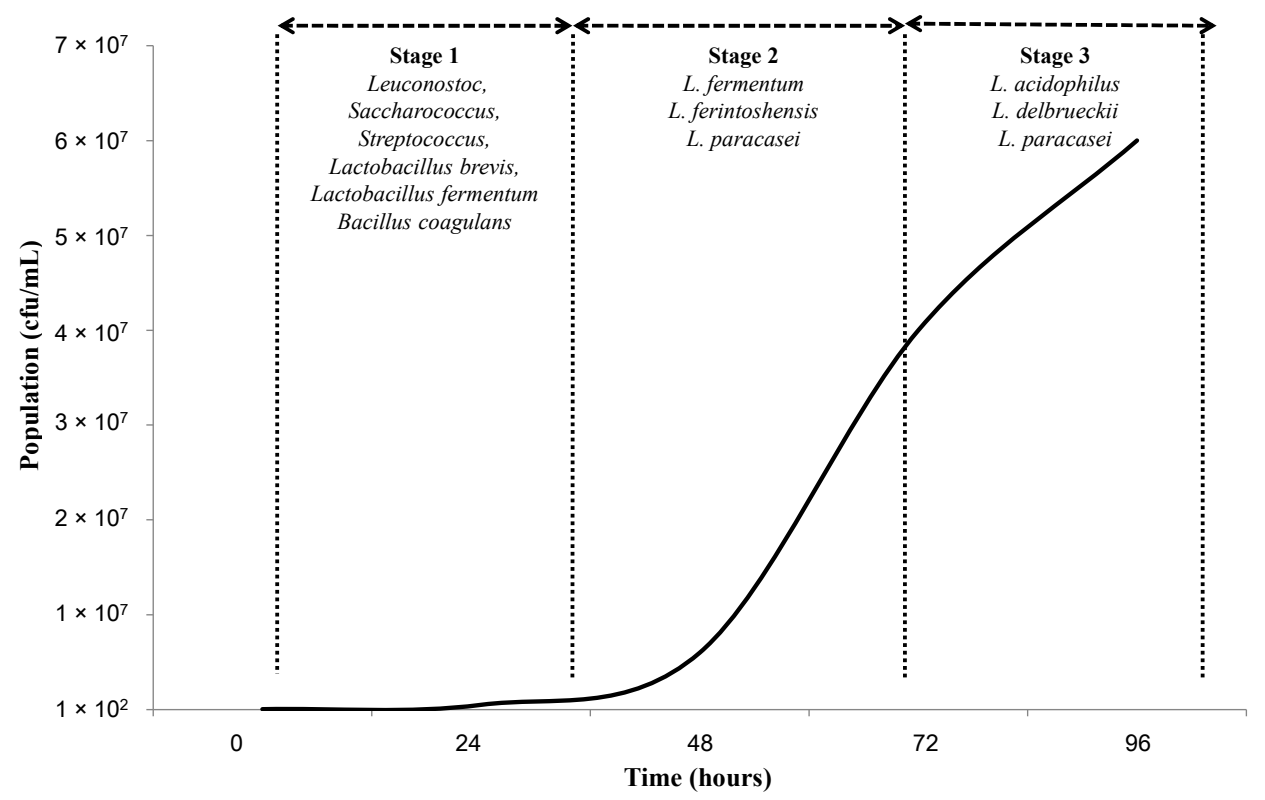

Figure 5. Evolution of lactic acid bacteria in a typical malt whisky fermentation (reproduced with permission from Wilson [8]).

Although LAB are the most predominant microbes, Neri [9] identified a range of wild yeasts that may be present such as non-distilling strains of Saccharomyces cerevisiae, Pichia membranefaciens, Torulaspora delbrueckii and Candida species. Their biochemical similarity to distilling yeast means that they are potentially problematic. However, the dominance of the main production yeast strain usually keeps the non-distilling population at a low level. As a result, a typical microbiological profile for a distillery fermentation is depicted as follows (see Figure 6).

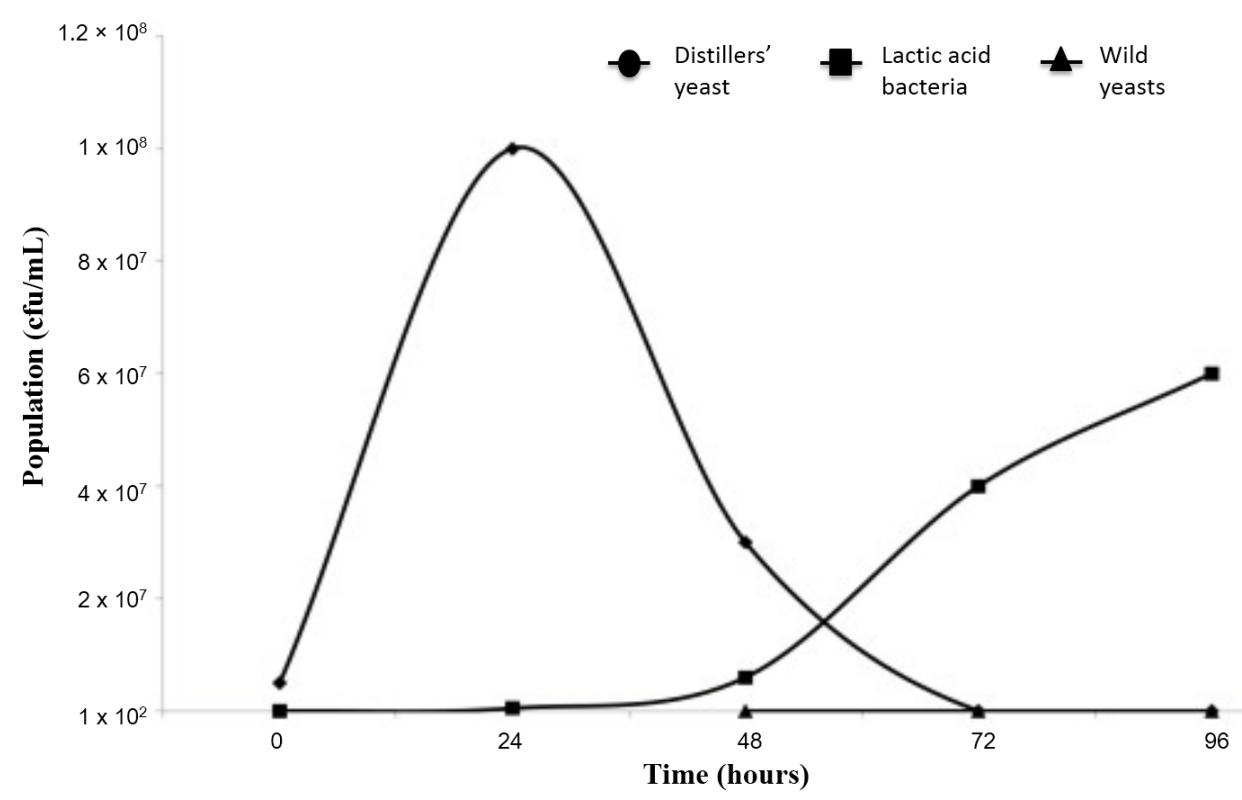

Figure 6. Evolution of microorganisms in a typical malt whisky fermentation (reproduced with permission from Wilson [8]). 
Completely non-contaminated fermentations may result in a reduction in the desirable esters and other congeners characterising the distilled spirit but, conversely, heavy contamination by competing bacteria can reduce spirit yields and produce undesirable off-flavours.

\subsection{Monitoring Whisky Fermentations}

In terms of assessing performance of a whisky fermentation process, various analytical techniques are available to both distillers and researchers. These are summarised in Table 2.

Table 2. Analytical techniques to monitor whisky fermentations.

\begin{tabular}{cc}
\hline Fermentation Performance Criterion & Analytical Method \\
\hline Spirit yield & Calculations based on conversion of cereal starch to ethanol \\
\hline Carbon dioxide evolution rate & Gas flow meter \\
\hline High gravity fermentation & Original gravity, yeast viability, pH decline \\
\hline Sugar utilisation spectrum (e.g., Maltotriose) & HPLC \\
\hline Spirit character (off-notes, fusel oils) & Sensory panel evaluation, olfactory GC \\
\hline Yeast viability/vitality and stress responses & Flow cytometry \\
\hline Distillery/Product/Application specific attributes & Genetic markers \\
\hline
\end{tabular}

While some of these are well established, modern techniques such as flow cytometry are able to provide an unprecedented level of detail regarding yeast viability, vitality and performance during fermentation [10]. There have also been advances in our understanding of yeast genetics and molecular biology, which will ultimately help researchers to select for more specific quality and performance traits (see Section 5.2). This may provide distillers not just consistent spirit quality for their existing products, but also enhanced flavour attributes to enable them to provide a wider range of products.

\subsection{S. cerevisiae in Whisky Fermentations}

S. cerevisiae is the predominant species of yeast employed in the production of worldwide distilled spirits. Table 3 shows some of the major attributes of $S$. cerevisiae as an ethanologen, together with some of the disadvantages.

Table 3. Saccharomyces cerevisiae as an ethanologen.

\begin{tabular}{cc}
\hline Advantages & Disadvantages \\
\hline Genome sequence and genetic tools well developed & $\begin{array}{c}\text { Cannot ferment: xylose, arabinose, cellobiose, } \\
\text { xylobiose, lactose, maltodextrins, etc. }\end{array}$ \\
\hline Relatively stress tolerant & Flocculence (desired or undesired) \\
\hline $\begin{array}{c}\text { Well developed for large scale } \\
\text { industrial fermentations }\end{array}$ & $\begin{array}{c}\text { Accumulates glycerol, trehalose, glycogen } \\
\text { (reduced ethanol yields) }\end{array}$ \\
\hline Generally regarded as safe (GRAS) status & Non-anaerobic (strict) growth \\
\hline Desirable flavour compounds produced & Crabtree positive and glucose repressed \\
\hline High ethanol $(>20 \% \mathrm{v} / \mathrm{v})$ possible. & Some strains genetically unstable \\
\hline
\end{tabular}

This yeast will readily ferment the sugars made available in wort following saccharification of cereal starches using malt or exogenous enzymes. The major products of this fermentative metabolism by yeast are ethanol, carbon dioxide and glycerol, and the minor compounds are a host of others including esters, aldehydes, higher alcohols, organic acids, diketones, sulphury and phenolic compounds (see Figure 7). 


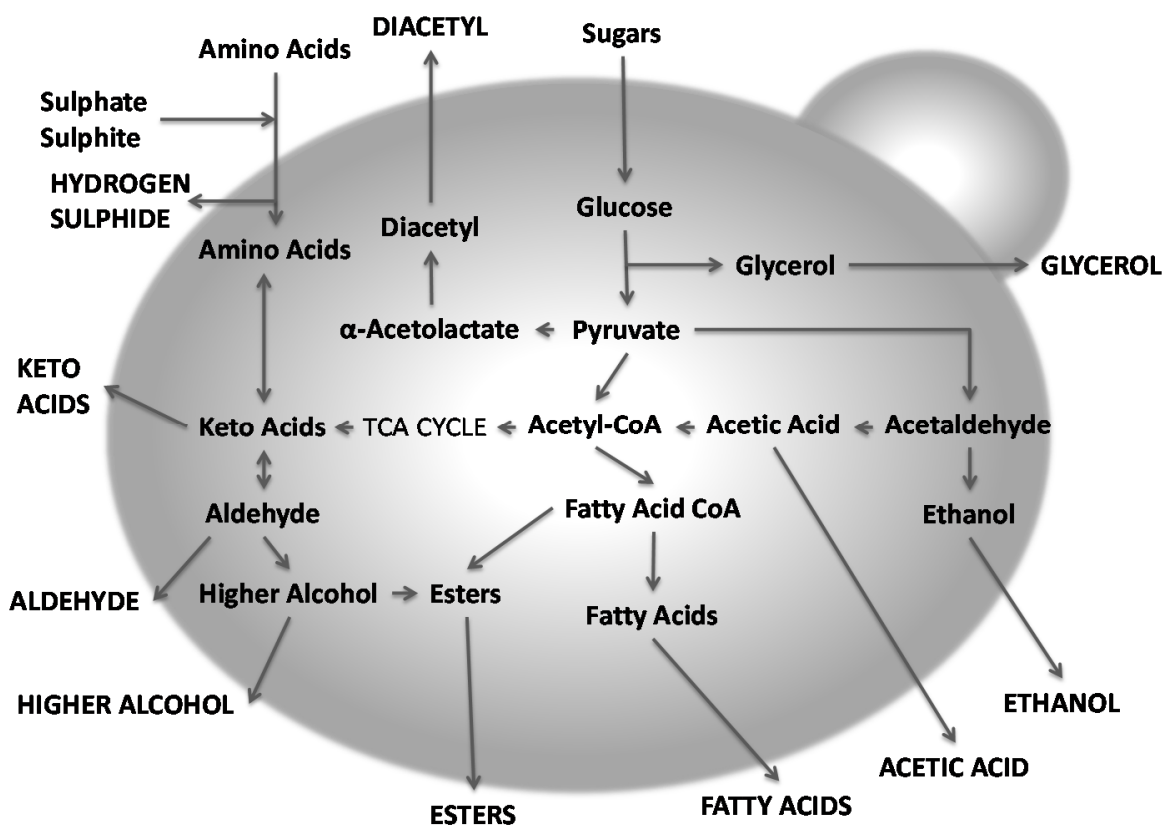

Figure 7. Summary of $S$. cerevisiae metabolic pathways yielding fermentation products.

Table 4 lists the major classes of spirit congeners produced by yeast metabolism. These minor yeast metabolites contribute greatly as flavour congeners in the final distilled spirit.

Table 4. List of congener classes produced by distilling strains of S. cerevisiae.

\begin{tabular}{|c|c|c|}
\hline Compound Class & Example & Flavour/Aroma \\
\hline \multirow{4}{*}{ Higher alcohols } & $n$-propanol & Alcoholic \\
\hline & Isobutanol & Pharmacy \\
\hline & Iso-amyl alcohol & Fusel, alcoholic, fruity, banana \\
\hline & $\begin{array}{l}\text { (3-methylbutan-1-ol) } \\
\text { Phenylethanol }\end{array}$ & Roses, perfume \\
\hline \multirow{8}{*}{ Esters } & Ethyl acetate & Solvent, acetone \\
\hline & Ethyl butyrate & Pineapple, Banana, mango \\
\hline & Ethyl caproate & Apple, aniseed \\
\hline & Ethyl caprylate & Apple \\
\hline & Ethyl hexanoate & Pineapple, unripe banana \\
\hline & Ethyl lactate & Butter/cream \\
\hline & Ethyl octanoate & Sour apple, apricot \\
\hline & Iso-amyl acetate & Banana, fruity \\
\hline Aldehydes & Acetaldehyde & Green apple \\
\hline Vicinal diketones & Diacetyl & Butter, butterscotch \\
\hline Phenolics & 4-Vinyl guaiacol & Clove-like \\
\hline S-Compounds & Hydrogen sulphide & Rotten eggs \\
\hline
\end{tabular}

As shown in Table 4, distilling strains of $S$. cerevisiae produce a wide range of congeners, the main ones being:

- Higher alcohols are produced by yeast as by-products of reactions involving amino acids and carbohydrates [11]. The most common of those is iso-amyl alcohol, which accounts for $40 \%-70 \%$ of the total higher alcohols. At low levels higher alcohols have a positive effect on the sensory properties of distillates but at higher concentrations iso-amyl alcohol in particular becomes unpleasant [12]. In addition, a high level of 1-propanol can indicate bacterial spoilage [13]. 
- Esters. In total, over 100 different ester compounds are formed during fermentation, predominantly imparting fruity notes to the spirit. Many esters are present at their flavour threshold in wash meaning that even small concentration changes can result in large impacts on flavour. Synergistic effects may also lead to flavour contributions from esters that are present below their threshold [14].

- Sulphur compounds are also produced during yeast amino acid metabolism and their presence contributes to the 'heaviness' or body of the spirit. Sulphur compounds may be re-assimilated by yeast or purged by $\mathrm{CO}_{2}$ produced during fermentation and levels are also influenced by copper contact during distillation [15].

- Vicinal diketones. Of the remaining congeners, the vicinal diketone, diacetyl is particularly problematic because it has similar volatility to ethanol and therefore is difficult to remove by distillation. Diacetyl off-flavours in beers and spirits are often described as being like rancid butter, or butterscotch.

- Organic acids such as acetic, butyric, caproic and isovaleric are also produced during fermentation by yeast. Levels are generally below flavour thresholds and due to their low volatility they can be eliminated during distillation. However, these acids play an important role in the formation of esters.

Several factors influence congener production in whisky fermentations, including:

- Yeast strain and yeast condition

- Yeast growth (e.g., increased $\mathrm{O}_{2}$ results in increased fusel alcohol production)

- Fermentation media (sugars, nitrogen, vitamins, minerals)

- Temperature (e.g., higher alcohols increase with temperature)

- Mixing (increases fermentation and higher alcohols)

- $\mathrm{CO}_{2}$ (reduces yeast growth and lowers fusel alcohols)

- Contamination (e.g., wild yeasts and lactic acid bacteria).

The wort composition will impact on congener production by yeast, and this includes not only the fermentable sugar, but also the available nitrogen and other nutrients including minerals. Regarding the latter, De Nicola et al. [16] showed that the levels of zinc in distiller's wort influenced the flavour attributes of the resulting spirits, particularly the concentrations of esters and fusel alcohols.

For whisky fermentations, the specific strain of $S$. cerevisiae that is used will also impact both on yields of alcohol obtained, and the levels of congeners that collectively contribute to the development of spirit flavour and aroma characteristics. Most S. cerevisiae strains produce more-or-less the same types of flavour compounds, but the relative concentrations will vary depending on the particular strain in question. Whisky distillers must therefore pay careful attention to the S. cerevisiae strain exploited to ensure consistency of fermentation performance and product quality. The yeast strains used by many whisky distillers are based on a small number of stable commercial S. cerevisiae strains, primarily derived originally from a baking/brewing (ale) yeast heritage. Distilling yeast differs from brewing yeast in terms of more complete wort fermentation, fully utilising the fermentable starch-derived sugars-mainly maltose, glucose, maltotriose, and (potentially) small maltodextrins. This contrasts with the yeasts for sugar and fruit based products which are developed to ferment sucrose, fructose and glucose, respectively (see article on wine in this Special Issue). The ability to efficiently and completely ferment maltotriose in cereal based worts is considered to be an important distinguishing characteristic of yeasts used suitable for Scotch whisky production. Also, distilling yeast strains used in Scotch whisky production, unlike brewing strains, are non-flocculent and are only used for a single fermentation cycle.

Although, in theory, there is a large selection of potential yeast strains that can be exploited for distilled spirits production, for Scotch Whisky, relatively few strains of S. cerevisiae are actually available commercially for distillers. These include: Distiller's M and MX yeast (From Kerry Bio-Science); 
Pinnacle Yeast (from AB Mauri); and DistillMax Yeast (from Lallemand). These yeasts are propagated as pure cultures in aerobic fed-batch processes on a large scale using molasses derived from sugar cane and sugar beet, together with other essential nutrients (e.g., ammonia/ammonium salts as additional available nitrogen). Distiller's yeasts are available in different formats; liquid (cream), cake (compressed) and dried (see Section 4). Yeast producers have the potential to deliver new strains of yeast, for example, those capable of efficiently fermenting a much wider range of substrates. Many such developments have been directed principally at the bioethanol (fuel alcohol) sector, and there are lessons to be learned for whisky distillers from these applications, specifically those involving genetic improvement strategies (see Section 5.2).

\subsection{Isolation of Yeasts from Distillery Environments}

The study of microbial resources in different ecosystems is beneficial due to their diversity and because of the biotechnological properties they might have on some applications, such as bioethanol and spirit beverages production amongst others [17,18]. A number of distillers, particularly craft distillers, are actively searching for production yeasts derived from either raw materials or the environment in order to bring something new to their products, be it improved flavor/aroma or a direct link to terroir $[19,20]$. Isolating microbes from environmental samples is quite straightforward. For example, for yeast, selective media such as yeast extract peptone dextrose (YPD) or Wallerstein laboratory nutrient (WLN) may be used to provide nutrients specifically suited to their growth. The addition of an antibacterial such as chloramphenicol and sodium propionate to suppress mould growth is usually employed in initial screenings and then Lysine medium may be used to distinguish between Saccharomyces sp. and non-Saccharomyces spp. The following Case Study exemplifies the approach of a craft distiller to isolate yeasts from distillery environments. For further information, see Burke, Speers and Hill [19].

Case Study: Isolation of Yeast from Lindores Abbey

The Abbey at Lindores, Newburgh (Fife, Scotland, UK) is attributed as "the birthplace of Scotch Whisky"; the first recorded transaction of malt for the specific purpose of production of aqua vitae by the Abbey monks may be found in the Exchequer records of 1494. The current owner of the Abbey, Drew Mackenzie-Smith, is developing a new distillery and education centre on neighbouring land for which a series of research projects have been carried out at the International Centre for Brewing and Distilling at Heriot-Watt University in Edinburgh. Two projects have focused on isolation of potential distilling yeast from the Abbey site. Both swab and air samples plated on Sabouraud agar (SAB), and Wallerstein laboratory nutrient agar (WLN) supplemented with chloramphenicol were used for initial isolation with colonies then examined by light microscopy to determine cell morphology. Tentative Saccharomyces colonies have then been included in fermentation tests using all-malt wort to examine their ability to rapidly attenuate wort, tolerate high levels of ethanol $(10 \%-12 \%$ abv $)$, and to flocculate at the end of fermentation. Several yeast strains have been isolated with characteristics close to distillers " $\mathrm{M}$ " yeast and therefore possess the potential to be employed as production yeast $[21,22]$.

\section{Yeast Formats and Yeast Management for Whisky Production}

\subsection{Yeast Formats for Whisky Production}

Although certain whisky distillers, for example, some in the US, propagate their own yeast cultures from laboratory stocks, most other distillers will rely on supplies of commercially available strains from yeast production companies [23]. For Scotch whisky producers, the main formats of distilling yeast are creamed, pressed and dried yeasts as shown in Figure 8. 

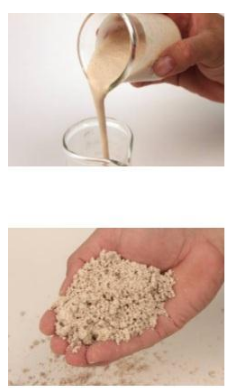

Compressed (or cake, or

crumbled) yeast

(solids content $30 \%-40 \%$ )

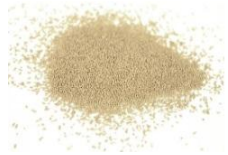

Dried yeast

(solids content 94\%-96\%)

Figure 8. Types of yeast formats available for whisky distillers.

\subsection{Yeast Management for Whisky Production}

Although some larger grain whisky distilleries in Scotland conduct rudimentary propagation of commercially supplied cream yeast, normally Scotch malt whisky distilleries do not propagate yeast. Instead, they add cream yeast (direct from yeast supply companies) to the wort, by injecting it into the wort line or in some cases put it directly into the fermentation vessel (or, "washback"), or add via a slurry tank. A small number of malt whisky distilleries utilise pre-multiplication conditioning steps (sometimes called the "bub" stage). This aerobic process maximises yeast activity to facilitate more rapid fermentation, particularly if high original gravity wort $\left(>1070\right.$ or $\left.17^{\circ} \mathrm{P}\right)$ is used. In contrast to breweries, Scotch whisky distilleries do not aerate wort or recycle their yeast. In addition, there is no yeast filtration step employed and the full contents of the fermenter (the "wash" or the "beer") are transferred to the distillation process. The presence of yeast in the fermented wash to be distilled is considered to give important benefits, especially in developing desirable spirit flavour attributes.

Producers of other similar products to Scotch whisky, such as Bourbon and Tennessee whiskey in USA, often propagate their own proprietary yeast strains, something that Scotch whisky distillers do not normally do. Although there is no technical reason for this, it is considered uneconomic for small Scotch malt whisky distillers to conduct yeast propagation on site. In addition, due to the relative close proximity of the yeast supply companies to the distilleries, it is more beneficial to obtain commercially supplied fresh yeast in terms of quality assurance, cost effectiveness and sustainability.

For a small number of distilleries, including craft distilleries, the use of dried yeast is very desirable. This is mainly due to the difficulty in transporting supplies of fresh yeast to distilleries-for example in remote areas of the Scottish Highlands and Islands. Dried yeast is also useful as a backup in case of failure or problems with other supplies. However, dried yeasts are not as prevalent as the pressed and cream yeast formats, which are more or less ubiquitous within the Scotch industry. Dried yeast strains of S. cerevisiae can offer some additional flavour versatility, since some are based on a wine yeast background (see Miles [24]), and can be popular with some specific distilleries looking for particular flavour characteristics associated with their products. Characteristics of different commercially-available yeast formats are summarised in Table 5, and have been further discussed by Richards [23].

Table 5. Characteristics of different S. cerevisiae formats for whisky distilling.

\begin{tabular}{ccccc}
\hline Yeast Format & Solids & Packaging & Storage & Shelf Life \\
\hline Cream & $15 \%-20 \%$ & Bulk & Refrigerate & 2 Weeks \\
Fresh Bag or Crumble & $30 \%-40 \%$ & Unprotected & Refrigerate & 2-6 Weeks \\
Instant Active Dry & $94 \%-96 \%$ & Protected & Room Temp & 3-4 Years \\
\hline
\end{tabular}


Until fairly recently, some Scotch malt whisky distillers used a proportion of brewers' yeast (typically $30 \%-50 \%$ of the pitching rate) obtained from the recycling of aged yeast from brewery fermentations. This was acid washed, repackaged and supplied to distilleries, and was considered to provide a useful supplement to normal distillers' yeast, in terms of supporting fermentation performance and providing additional flavour complexity. However, in Scotland the use of brewer's yeast was largely phased out by distillers during the late 1990's and mid 2000's. Although the benefits of using brewer's yeast for whisky fermentations have been reported [25] brewer's yeast is used by only a very small number of distilleries for 'traditional' reasons. For Scotch malt whisky fermentations, the main commercial yeast demands are for pressed and/or cream distilling yeasts, to ensure consistency of fermentation performance, efficient utilisation of substrate (maltose/maltotriose), high alcohol yields, and most importantly, spirit flavour consistency.

Comparing Scotch grain and malt whisky fermentation requirements, these are fundamentally similar but the main difference is one of scale. For example, the grain whisky distiller's aim is to produce the maximum quantity of alcohol from the raw materials, within the confines of the legal definition of Scotch whisky production. This can be facilitated by fermenting cereal-derived worts in larger batches, but with less yeast, and in grain distilleries yeast pitching rates are generally much lower (about 25\%) compared with that used for malt whisky production. Although there is also an interest in the flavour attributes of grain spirits, these are far less important than for malt whisky. This means that grain distillers can operate closer to the process limits for alcohol yields, particularly by increasing wort specific gravity, to levels approaching $1080^{\circ}\left(19-20^{\circ}\right.$ Plato). Consequently, grain distillers are more likely to operate under more stressful conditions, such as high original gravity, higher alcohol strength $(>10 \% \mathrm{v} / \mathrm{v})$ and at elevated temperatures, and it is essential for yeasts to tolerate these stressful conditions and continue to ferment efficiently. Stress-tolerance in S. cerevisiae whisky yeasts is thus a key desirable attribute (see Section 5.1). Hence, as well as the standard yeasts used for malt distilling, grain distillers may also use additional yeast strains that are better adapted to perform well under stressful conditions.

\section{New Developments for S. cerevisiae in Whisky Production}

\subsection{Key Attributes for New Distilling Yeast Strains}

Walker et al. [26] have identified 6 key attributes for new distilling yeast strains that could be prioritised to deliver strong potential benefits for whisky distillers (see Table 6). These include (1) consistency of flavour; (2) temperature tolerance; (3) increased fermentation rate; (4) increased alcohol tolerance; (5) increased substrate tolerance; and (6) increased substrate utilisation. It is clear that these attributes are also highly relevant for fermentations for other potable distilled spirits (see Table 7), as well as potentially for bioethanol production.

Table 6. Desired attributes for new whisky distilling yeast strains.

\begin{tabular}{|c|c|}
\hline Parameter & Aspirational Target \\
\hline Spirit flavour & Consistently having the sensory characters associated with whisky \\
\hline Temperature tolerance & $\begin{array}{l}\text { Have the ability to withstand and operate efficiently at temperatures up to } \\
\qquad 37-38^{\circ} \mathrm{C} \text { (aspiring to } 40^{\circ} \mathrm{C} \text { ) }\end{array}$ \\
\hline Fermentation rate & The ability to reduce fermentation times substantially, perhaps to less than $30 \mathrm{~h}$ \\
\hline Alcohol tolerance & $\begin{array}{c}\text { Display increased alcohol tolerance and be able to produce up to } 15 \%(\mathrm{v} / \mathrm{v}) \\
\text { alcohol (or higher) }(12 \%(\mathrm{v} / \mathrm{v}) \text { for malt distilleries) }\end{array}$ \\
\hline Substrate tolerance & $\begin{array}{l}\text { Capable of operating efficiently at higher original specific gravities up to } \\
1080 \text { or even } 1100^{\circ}\end{array}$ \\
\hline Substrate utilisation & Reduce biomass and waste (co-) product production and form more alcohol \\
\hline
\end{tabular}


With increasing environmental sustainability issues facing the whisky industry, particularly those concerned with more efficient energy and water use, there is a growing awareness that criteria for selecting new distilling yeasts should take such issues into account. Scotch whisky distillers are addressing these and many are conducting fermentations with increased wort concentration (specific gravity) to produce higher alcohol strength, as well as fermenting at higher temperatures. The latter can reduce the need for cooling, but will place additional stress on the yeast, compromising fermentation efficiency. This may also impact on spirit quality, which is a primary production and quality objective of Scotch whisky distillers. Addressing these sustainability impact issues through yeast and fermentation means focusing on specific new yeast attributes that include increased stress tolerance (thermotolerance, osmotolerance, alcohol tolerance). Walker et al. [26] have indicated that the fuel alcohol sector will likely drive the development of new yeasts for distilled spirits.

\subsection{S. cerevisiae Strain Improvement for Whisky Production}

Table 7 highlights the key desirable properties of distiller's yeast strains employed for various types of distilled spirit fermentations. These include whisky and neutral spirit fermentations based on starchy/cereal substrates and rum and cognac fermentations based on sugar and fruit, respectively.

Table 7. Qualitative criteria in evaluating desired attributes of new distilling strains of S. cerevisiae (Adapted from [26]).

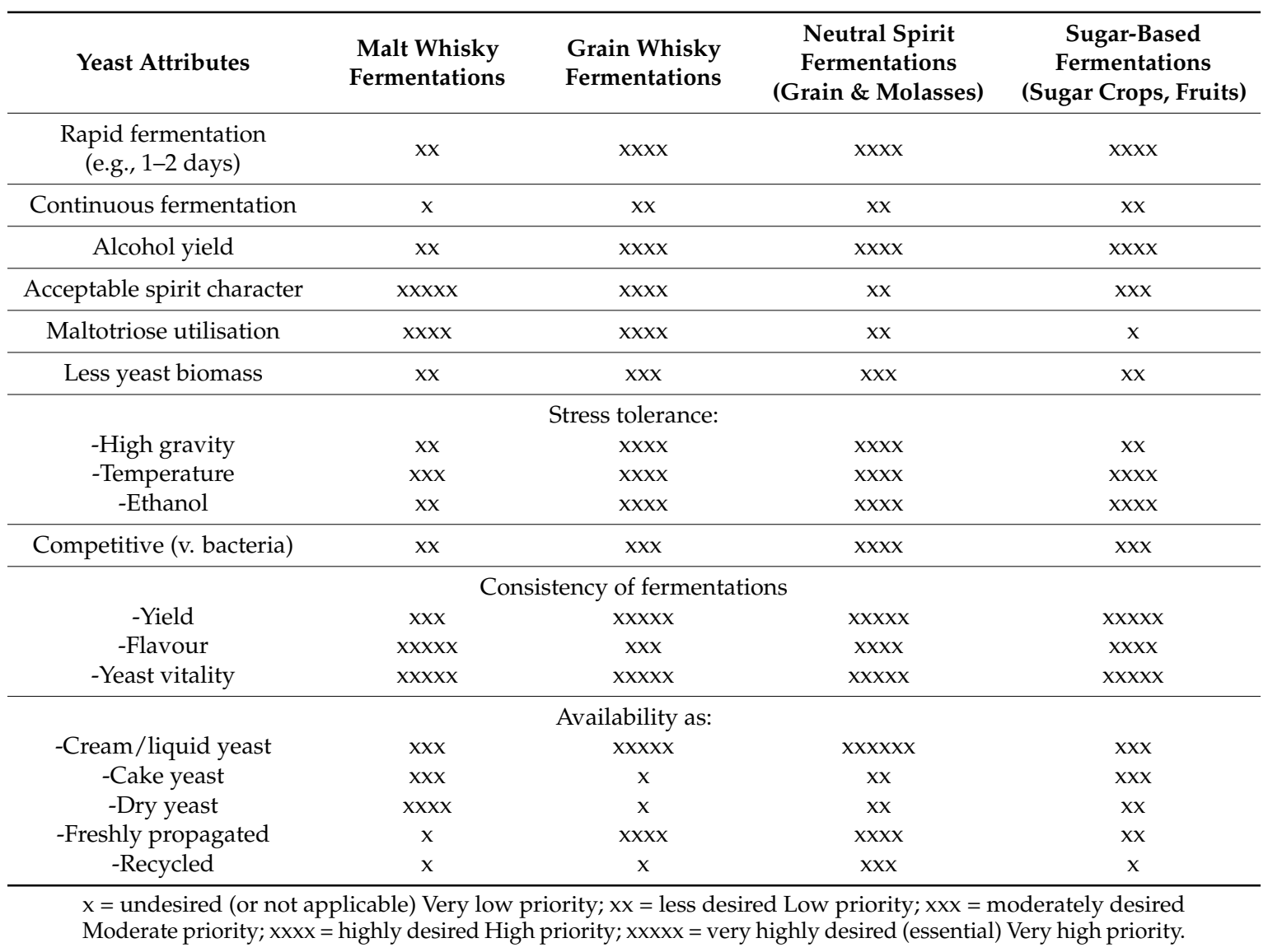

Such information may provide useful qualitative guidance for distillers, researchers and yeast manufacturers to select new strains of $S$. cerevisiae. Research into the genetic aspects controlling yeast attributes will lead to a more fundamental understanding of S. cerevisiae and ultimately how it behaves under whisky production conditions. Other research areas for the whisky industry 
include development of new yeast attributes that can used to improve production and flavour quality requirements in addition to meeting sustainability targets.

In addition, there are also opportunities for whisky producers to introduce new yeast strains and to adopt alternative ways of processing their co-products, such as spent grains and pot ale (see [27]).

\section{Conclusions}

Whisky production is centuries old, but research into new distilling yeast strains has been progressed significantly in recent years. Distillers can now produce a diverse range of potable spirits more efficiently and sustainably, including whiskies. Modern analytical techniques in molecular genetics are now available to look at the characteristics of promising new $S$. cerevisiae yeasts in much more detail, and to conduct directed strain engineering protocols. This means that there are tools available that can provide suitable yeast strains to fulfil requirements of whisky distillers. However, it is unlikely that distilled spirits producers will be adopting GM yeasts in the foreseeable future, due primarily to adverse public perceptions. Where advances in yeast strain engineering are being adopted are in the bioethanol sector. For example, new GM strains are now commercially available for fuel alcohol production that maximise ethanol production and improve process tolerance (see [28]).

Scotch whisky is a 'traditional' industry with a strong cultural and regional identity. Legal constraints limit the options available to Scotch whisky distillers to address sustainability issues and deliver production improvements in ways that other distillers are not. Nevertheless, new yeast strains offer one of the few realistic options for delivering process improvements. Present challenges for whisky distillers include initiatives to reduce demands for energy, use less water and improve the utilisation of co-products. New S. cerevisiae strains can be expected to deliver more efficient fermentation performance under more highly stressed conditions. Therefore, it is now more important for distillers to stimulate research into new yeasts that will be capable of fulfilling these objectives.

Conflicts of Interest: The authors declare no conflict of interest.

\section{References}

1. Scotch Whisky Association Information. Available online: http://www.scotch-whisky.org.uk/ (accessed on 27 October 2016).

2. Palmer, G.H. Cereals in Malting and Brewing. In Cereal Science and Technology; Palmer, G.H., Ed.; Aberdeen University Press: Aberdeen, UK, 1989; pp. 61-242.

3. Pyke, M. The manufacture of Scotch grain whisky. J. Inst. Brew. 1965, 71, 209-218. [CrossRef]

4. Geddes, P. Bacteriology in the Scotch whisky industry. J. Inst. Brew. 1985, 91, 56-57.

5. Dolan, T.C.S. Bacteria in whisky production. Brewer 1979, 65, 60-64.

6. Dolan, T.C.S. Some aspects of the impact of brewing science on Scotch malt whisky production. J. Inst. Brew. 1976, 82, 177-181. [CrossRef]

7. Wilson, N. The Effect of Lactic Acid Bacteria on Congener Composition and Sensory Characteristics of Scotch Malt Whisky. Ph.D. Thesis, Heriot-Watt University, Edinburgh, UK, 2008.

8. Wilson, N. Contamination: Bacteria and wild yeast in a whisky fermentation. In Whisky: Technology, Production and Marketing; Russell, I., Stewart, G.G., Eds.; Elsevier: London, UK, 2014; pp. 147-154.

9. Neri, L. The Involvement of Wild Yeast in Malt Whisky Fermentations. Ph.D. Thesis, Heriot-Watt University, Edinburgh, UK, 2006.

10. Da Silva, T.L.; Roseiro, J.C.; Reis, A. Applications and perspectives of multi-parameter flow cytometry to microbial biofuels production processes. Trends Biotech. 2012, 30, 225-232. [CrossRef] [PubMed]

11. Briggs, D.E.; Boulton, C.A.; Brookes, P.A.; Steven, R. Brewing: Science and Practice; Woodhead Publishing: Cambridge, UK, 2004.

12. Russell, I.; Bamforth, C.; Stewart, G.G. Whisky: Technology, Production and Marketing; Elsevier: London, UK, 2003.

13. Plutowska, B.; Biernacka, P.; Wardencki, W. Identification of Volatile Compounds in Raw Spirits of Different Organoleptic Quality. J. Inst. Brew. 2010, 116, 433-439. [CrossRef] 
14. Verstrepen, K.J.; Derdelinckx, G.; Dufour, J.-P.; Winderickx, J.; Thevelein, J.M.; Pretorius, I.S.; Delvaux, F.R. Flavor-active esters: Adding fruitiness to beer. J. Biosci. Bioeng. 2003, 96, 110-118. [CrossRef]

15. Harrison, B.; Fagnen, O.; Jack, F.; Brosnan, J. The impact of copper in different parts of malt whisky pot stills on new make spirit composition and aroma. J. Inst. Brew. 2011, 117, 106-112. [CrossRef]

16. De Nicola, R.; Hall, N.; Melville, S.; Walker, G. Influence of zinc on distiller's yeast: Cellular accumulation of zinc and impact on spirit congeners. J. Inst. Brew. 2009, 115, 265-271. [CrossRef]

17. Úbeda, J.F.; Chacón-Ocaña, M.; Díaz-Hellín, P.; Ramírez-Pérez, H.; Briones, A. Genetic and phenotypic characterization of Saccharomyces spp. strains isolated in distillery plants. FEMS Yeast Res. 2016, 16, fow035. [CrossRef] [PubMed]

18. Chandrasena, G.; Keerthipala, A.P.; Walker, G.M. Isolation and characterisation of Sri Lankan yeast germplasm and its evaluation for alcohol production. J. Inst. Brew. 2006, 112, 302-307. [CrossRef]

19. Burke, C.; Speers, R.A.; Hill, A.E. Investigating the Birthplace of Scotch Whisky: Microbiological Survey of Lindores Abbey. In Distilled Spirits. Future Challenges, New Solutions; Goodall, I., Fotheringham, R., Murray, D., Speers, R.A., Walker, G.M., Eds.; Context Products Ltd.: Packington, UK, 2015; pp. 249-256.

20. Crisp, J. Selection of Yeast Strains for Use at the Dornoch Distillery Company. Master's Thesis, Heriot-Watt University, Edinburgh, UK, 2016.

21. Burke, C. Yeast Isolation and Identification from Lindores Abbey, the Birthplace of Scotch Whisky. Master's Thesis, Heriot-Watt University, Edinburgh, UK, 2013.

22. Robitaille, J.L. Isolation of Distiller's Yeast from Lindores Abbey Grounds. Master's Thesis, Heriot-Watt University, Edinburgh, UK, 2016.

23. Richards, C. Diversity of yeast supply for distilled spirit fermentations. In Distilled Spirits. Future Challenges, New Solutions; Goodall, I., Fotheringham, R., Murray, D., Speers, R.A., Walker, G.M., Eds.; Context Products Ltd.: Packington, UK, 2015; pp. 37-41.

24. Miles, J. Different yeast strains achieve different new-make spirit flavours. In Distilled Spirits. Future Challenges, New Solutions; Goodall, I., Fotheringham, R., Murray, D., Speers, R.A., Walker, G.M., Eds.; Context Products Ltd.: Packington, UK, 2015; pp. 205-208.

25. Piggott, J.R.; Sharp, R.; Duncan, R.E.B. Science and technology of whiskies. In Longman Scientific E Technical; Wiley \& Sons: New York, NY, USA, 1989.

26. Walker, G.M.; Brosnan, J.; Bringhurst, T.; Jack, F. Selecting new distilling yeasts for improved fermentation and for sustainability. In Distilled Spirits. Science and Sustainability, Proceedings of the 4th Worldwide Conference on Distilled Spirits; Walker, G.M., Goodall, I., Fotheringham, R., Murray, D., Eds.; Nottingham University Press: Nottingham, UK, 2012; pp. 127-136.

27. Bennett, J.; Walker, G.; Murray, D.; Akunna, J.; Wardlaw, A. Avenues for bioenergy production using malt distillery coproducts. In Distilled Spirits. Future Challenges \& New Solutions, Proceedings of the 5th Worldwide Conference on Distilled Spirits, Glasgow, UK; Goodall, I., Fotheringham, R., Murray, D., Speers, A., Walker, G.M., Eds.; Context Publishers: Nottingham, UK, 2015; pp. 303-312.

28. Argyros, A.; Stonehouse, E. Mascoma Corporation, Lebanon, NH, USA. Yeast strain development for alcohol production. In The Alcohol Textbook, 6th ed.; Walker, G.M., Ingledew, W.M., Abbas, C., Pilgrim, C., Eds. 2017, to be published.

(C) 2016 by the authors; licensee MDPI, Basel, Switzerland. This article is an open access article distributed under the terms and conditions of the Creative Commons Attribution (CC-BY) license (http://creativecommons.org/licenses/by/4.0/). 